\title{
O USO DA APRENDIZAGEM BASEADA EM PROBLEMAS (PBL) COMO METODOLOGIA PEDAGÓGICA NOS CURSOS SUPERIORES EM ADMINISTRAÇÃO.
}

\author{
Diego L.P Andreasi, Carmen Lúcia Dias, Sidinei de Oliveira Sousa \\ Universidade do Oeste Paulista - UNOESTE, Mestrado em Educação, Presidente Prudente, SP. E-mail: \\ gpdiego@hotmail.com
}

\begin{abstract}
RESUMO
Ao contrário do modelo tradicional de ensino, que trata os alunos como meros receptores passivos de conhecimentos, a Aprendizagem Baseada em Problemas ou PBL (Problem-Based Learning), utiliza problemas para incentivar, motivar, e principalmente, promover a aprendizagem por meio de um desiquilíbrio cognitivo. O método surgiu no final da década de 60 , com o intuito de aprimorar o ensino das matérias relacionadas a área da saúde, entretanto, com o passar dos anos, outras áreas também começaram a utilizá-lo, sendo uma delas a de Administração. Dessa forma, esse artigo tem por objetivo discutir a importância do PBL no ensino superior em Administração com base nas publicações científicas sobre o tema nos últimos 5 anos. Para tal, utilizou-se como metodologia a revisão de literatura, na qual foram pesquisados artigos, dissertações e teses disponíveis na base de dados da Capes e na biblioteca virtual da SciELO. Como resultado, concluiu-se que apesar do método apresentar importantes vantagens quando utilizado, sua aplicação ainda está longe de ser uma unanimidade, tanto por parte dos alunos envolvidos, como de seus professores.
\end{abstract}

Palavras-chave: PBL, Aprendizagem, Curso, Ensino Superior, Administração.

\section{THE USE OF PROBLEM-BASED LEARNING (PBL) AS A PEDAGOGICAL METHODOLOGY IN HIGHER EDUCATION MANAGMENT COURSES.}

\begin{abstract}
Unlike traditional teaching model that treats the students as passive recipients of knowledge, the Problem-Based Learning method or PBL (Problem-Based Learning) uses problems to encourage, motivate, and mostly to promote learning through a cognitive dissonance. The method was launched in the late 60 's, in order to improve the teaching on subjects related to health, however, over the years; other fields have also begun to use it, such as the management field. Thus, this article seeks to discuss the importance of PBL in higher education management based on the last 5 years scientific publications on the subject. To this end, a literature review was used as the methodology, where articles, dissertations and theses were researched in the Capes database and in the virtual library SciELO. As a result, it was concluded that although the PBL method has important advantages when it is used, its application is still far from being unanimous by both the students involved and their teachers.
\end{abstract}

Keywords: PBL, Learning, Class, Higher Education, Management. 


\section{INTRODUÇÃO}

Vivemos em um mundo cada vez mais interconectado, movido não só por grandes avanços tecnológicos, como também por importantes mudanças econômicas, ambientais e sociais. Neste contexto, para que um indivíduo alcance sucesso profissional no dinâmico e concorrido mercado de trabalho de hoje, este precisa estar apto para desenvolver diversos tipos de habilidades consideradas pouco convencionais em um passado não muito distante, como: iniciativa, rápida capacidade de resolver problemas, ética, colaboração, sensibilidade para os impactos de suas decisões no ambiente e na sociedade, ou seja, este profissional precisa adquirir novos conhecimentos de maneira flexível e dinâmica, tudo isso colaborando dentro de grupos de trabalho compostos por diversas particularidades comportamentais.

Diante deste ambiente, discute-se que o método de ensino tradicionalmente utilizado nas escolas e universidades, o qual é fundamentado na transmissão e recepção de conhecimentos fixos e acabados, não vem conseguindo mais promover a aprendizagem de outras formas de conhecimento, como os procedimentais e atitudinais, tão valorizados na vida profissional e social (ZABALA, 1998). Sendo assim, os métodos tradicionais, nos quais os alunos são vistos como recipientes vazios a espera de receber o conhecimento passado pelo professor, o único detentor da sabedoria dentro da sala de aula, começaram a ter o seu valor questionado (FILHO; RIBEIRO, 2007).

Nessa perspectiva educacional, predomina o modelo que Freire (1981) intitula de "ensino bancário". Este modelo desestimula a curiosidade e o poder criativo do estudante e do professor, uma vez que exalta fórmulas prontas ao considerar que o processo de ensinar é apartado do aprender, ou seja, o "bancarismo" concebe um meio padronizado para a atuação do professor, ignorando os diferentes níveis cognitivos que os estudantes apresentam. Desta forma, é preciso promover de forma prioritária nos alunos a autonomia e o senso crítico na aprendizagem, para que estes possam buscar e criar novos conhecimentos durante toda a sua vida fora do ambiente acadêmico (DIAZ-BORDENAVE; PEREIRA, 2007). Ou seja, o professor deve promover a autonomia intelectual do aluno, sendo este o responsável pela própria aquisição do conhecimento.

Segundo Neves (2006), esse "novo" cenário educacional leva os estudantes a não desejarem mais saber como funciona, mas, sim, fazer funcionar, interagir com a realidade, representando, portanto, um desafio às clássicas aulas expositivas que, mesmo com a ajuda de recursos audiovisuais, podem não se tornarem atrativas para esse novo perfil de ingressante. Dessa forma, o estudante poderá ter dificuldades para assimilar essas aulas expositivas com o apoio de imagens estáticas. $\mathrm{O}$ autor ainda conclui dizendo que se não houver receptividade no meio educacional frente as características de linguagem e comportamento interativo desses jovens, conflitos e indisciplinas podem ser gerados dentro das salas de aula.

Uma área particularmente afetada por essas transformações é o ensino da Administração, já que grande parte do conteúdo que é transmitido pelos professores aos alunos em sala costuma ter aplicação imediata fora dela, pois, na maioria das vezes, estes já exercem outras atividades em suas empresas enquanto estudam, cumprindo uma dupla e cansativa jornada diária.

Embora se reconheça a importância desses conceitos, a questão que se coloca frente as instituições de ensino de modo geral é como incorporar um escopo crescente de conhecimentos e como desenvolver habilidades e atitudes necessários à boa atuação do profissional sem sobrecarregar as disciplinas, estender os cursos ou sobrecarregar os professores?

Uma das formas de conseguir resolver essa problemática seria através da utilização do Problem Based Learning (PBL), no Brasil conhecido por Aprendizagem Baseada em Problemas, já que esta abordagem educacional é reconhecida por oferecer aos alunos um meio de adquirir conhecimentos e desenvolver habilidades e atitudes valorizadas na vida profissional sem a necessidade de disciplinas ou cursos especialmente concebidos para esse fim (RIBEIRO, 2008). 
Neste contexto, este artigo tem por objetivo discutir a importância do PBL no ensino superior em Administração com base nas publicações científicas sobre o tema nos últimos 5 anos.

\section{UM BREVE HISTÓRICO SOBRE A APRENDIZAGEM BASEADA EM PROBLEMAS (PBL)}

O PBL é um método no qual visa o aprendizado a partir da resolução de problemas contextualizados na realidade em que os estudantes, após sua formação, poderão encontrar. Organizados em pequenos grupos compostos geralmente por 3 a 5 estudantes, no qual um dos alunos deverá exercer o papel de redator, o outro o de líder, e o outro, o de porta-voz, os discentes são motivados a buscar conhecimentos necessário à resolução dos problemas dentro do ambiente aos quais eles já estão inseridos. Já os princípios que formam a base do PBL, segundo Ribeiro (2008), podem ser encontrados nos estudos de Dewey, Bruner, Auzubel, Paulo Freire, entre outros.

É importante frisar que nesse método o professor passa a atuar como um "facilitador" que supervisiona o desenvolvimento do trabalho circulando entre os grupos, trazendo à tona determinados conhecimentos prévios, questionando entendimentos equivocados, incentivando, e principalmente, tirando dúvidas. Dessa forma, o aprendizado deixa de ser centrado exclusivamente no professor e começa a ser direcionado ao aluno, o qual deixa de ser um mero receptor passivo de conhecimentos, passando a atuar como principal responsável pelo seu aprendizado.

Resgatando um pouco de sua origem, as primeiras faculdades que utilizaram o método de PBL em suas disciplinas foram as faculdades de medicina de Mcmaster (Canadá) e de Maastricht (Holanda) no final da década de 60 e início da década de 70. Em seguida, foram as faculdades de Medicina de Albuquerque, Harvard e Hawaii, o qual posteriormente passou a ser recomendado e adotado, nas décadas seguintes, por diversas outras faculdades de medicina, enfermagem, fisioterapia, odontologia e veterinária (OLIVEIRA; ARRUDA; BITTENCOURT, 2007). Já no Brasil, o método ganhou notoriedade acadêmica ao ser utilizado nas disciplinas de enfermagem da Universidade Estadual de Londrina (UEL) por Berbel (1995).

Entretanto, apesar do PBL ter sido concebido originalmente para o ensino de cursos da área da saúde, seus conceitos se mostraram versáteis para possibilitar seu uso no ensino de outras áreas do conhecimento, como Engenharia da Computação, Física, Química, Engenharia Civil, Ciências Contábeis, dentre outras. Já no ensino da Administração, o curso com o maior número de alunos matriculados do Brasil segundo pesquisa do INEP (2014), pouco se conhece sobre a aplicação da metodologia PBL, visto a escassa publicação de trabalhos nessa área, além dos poucos casos em que se tem conhecimento de docentes de Administração propondo metodologias nesse sentido.

O PBL, como método de ensino na Administração, visa atender à necessidade tanto de professores como de estudantes, em relação ao ensino e aprendizagem. Do professor, porque estará adquirindo os conhecimentos necessários para a sua atuação. Do estudante, pois o método pode possibilitar, por meio da resolução de problemas reais ou próximos da realidade, a curiosidade e a busca pela pesquisa, tornando-o capaz de aprender a aprender, a ser crítico e obter uma aprendizagem duradoura (SOARES, 2008).

\section{O PBL COMO METODOLOGIA PEDAGÓGICA NOS CURSOS SUPERIORES EM ADMINISTRAÇÃO}

Devido ao amplo campo de trabalho ao qual o administrador pode atuar, este precisa estar apto a conhecer diversas outras áreas de ensino, como direito, informática, sociologia, psicologia, marketing, produção, dentre outras. A essa diversificação de disciplinas, soma-se a instabilidade do mercado de trabalho do administrador, que pode fazer com que esse profissional assuma durante sua vida, diferentes posições dentro de diferentes empresas e setores produtivos, ou mesmo abra seu próprio negócio, como bem demonstra a mais recente pesquisa do Instituto 
Endeavor Brasil (2014), que apontou que de cada 10 universitários brasileiros, 6 possuem vontade de empreender.

Dessa forma, nota-se a importância de utilizar-se o PBL no ensino da Administração, visto que uma das preocupações desse método é trabalhar justamente a questão da interdisciplinaridade, ou seja, a integração entre os conhecimentos adquiridos em diversas disciplinas, que como mencionado anteriormente, é fundamental para a boa formação do Administrador. Além disso, a formulação dos problemas utilizados na metodologia deve necessariamente levar em conta a realidade ao qual esses alunos estão inseridos, gerando assim um estímulo ao processo de aprendizagem, já que o estudante poderá aplicar imediatamente em sua empresa as teorias discutidas em sala de aula.

Segundo Filho e Ribeiro (2007, p.8), o método PBL, mesmo quando adotado parcialmente, parece ser vantajoso em comparação com abordagens instrucionais expositivas. Segundo os autores:

Apesar de implicar certo grau de imprevisibilidade e de exigir maior tempo de dedicação, o PBL parece contribuir bastante não apenas para que o docente se sinta mais satisfeito com as atividades de ensino, mas também para estimular seu aperfeiçoamento profissional mediante os desafios intelectuais que the são colocados pelos alunos.

Reforçando essa perspectiva, Andrade (2002) afirma que é fundamental que os docentes, discentes e instituições de ensino pesquisem, discutam e experimentem alternativas com o objetivo de melhorar a eficiência e a eficácia do processo de ensino-aprendizagem, preenchendo as lacunas geradas pela continuidade dos métodos tradicionais.

\section{METODOLOGIA}

Por se tratar de uma revisão de publicações que analisam o desenvolvimento de uma determinada temática dentro de um recorte de tempo, o presente trabalho utilizou como metodologia a revisão de literatura (MOREIRA, 2004). A pesquisa foi feita em revistas científicas, dissertações e teses disponíveis na base de dados da Capes e na biblioteca virtual da SciELO, sendo que o último acesso ocorreu em 02 de agosto de 2016. Como critérios de inclusão, foram utilizados para consulta os termos "Aprendizagem Baseada em Problemas", "Administração" e "Ensino Superior". Com relação ao período, foram selecionados os artigos publicados nos últimos 5 anos. Dessa forma, conforme demonstrado na Tabela 1, 5 artigos atenderam a essas exigências, sendo que 3 estão localizados na base de dados da Capes e 2 na biblioteca virtual da SciELO. 
Tabela 1. Resultado dos termos pesquisados, segundo autor, ano de publicação e base de dados

\begin{tabular}{|l|l|c|}
\hline $\begin{array}{l}\text { Avaliação da percepção de discentes e docentes sobre novas } \\
\text { tecnologias de ensino em cursos de graduação em } \\
\text { Administração }\end{array}$ & $\begin{array}{l}\text { Pádua Junior; Castilho } \\
\text { Filho; Steiner Net; } \\
\text { Akel Sobrinho (2014) }\end{array}$ & CAPES \\
\hline $\begin{array}{l}\text { Gestão e conhecimento nas ciências sociais aplicadas: uma } \\
\text { experiência didática relacionada ao ensino-aprendizagem da } \\
\text { disciplina de Filosofia da Administração }\end{array}$ & $\begin{array}{l}\text { Bazanini; Santana } \\
(2015)\end{array}$ & CAPES \\
\hline $\begin{array}{l}\text { Aprendizagem ativa em Administração: um estudo na } \\
\text { aprendizagem baseada em problemas (PBL) na graduação }\end{array}$ & $\begin{array}{l}\text { Souza, Verdinelli } \\
\text { (2013) }\end{array}$ & CAPES \\
\hline $\begin{array}{l}\text { A avaliação de estudantes e professores de administração } \\
\text { sobre a experiência com a aprendizagem baseada em } \\
\text { problemas }\end{array}$ & $\begin{array}{l}\text { Guedes, Andrade, } \\
\text { Nicolini (2015) }\end{array}$ & SciELO \\
\hline $\begin{array}{l}\text { Aprendizagem Baseada em Problemas: um método de } \\
\text { ensino-aprendizagem e suas práticas educativas. }\end{array}$ & $\begin{array}{l}\text { Borochovicius; } \\
\text { Tortella (2014) }\end{array}$ & SciELO \\
\hline
\end{tabular}

Fonte: Os pesquisadores

\section{DISCUSSÃO E ALGUMAS CONSIDERAÇÕES}

No que se refere-se à percepção dos alunos sobre o método, acredita-se que pelo fato de boa parte deles estar acostumada com os modelos educacionais tradicionais que promovem a recepção passiva dos conhecimentos, dependendo do professor como fonte única de conceitos teóricos formatados, sua utilização, apesar de ser aprovada pela maioria, ainda está longe de ser uma unanimidade. $O$ fato é que muitos ainda não se adaptaram a um ambiente de aprendizagem colaborativa e autodirigida (PÁDUA JUNIOR et al, 2013).

Já em relação a percepção dos docentes, supõe-se que pelo fato do PBL exigir uma maior dedicação destes, isso poderia acabar prejudicando suas demais atividades fora do ambiente educacional, como é sabido que muitos docentes do ensino superior em Administração exercem. Além do que, muitos professores são vencedores nos modelos tradicionais de ensino e, assim, podem não conseguir ver a necessidade de mudanças didáticas em suas aulas (GUEDES; ANDRADE; NICOLINI, 2015). Dessa forma, o método também encontrou certa resistência por parte de uma minoria destes profissionais.

Ainda sobre esse público, chamou-nos a atenção o fato de que mesmo professores com décadas de atuação na docência, boa parte deles jamais tinha ouvido falar sobre o PBL. Esse pode ser mais um fator prejudicial para a aplicação do método, pois segundo Guedes, Andrade e Nicolini (2015, p. 93), "se esses não estiverem preparados para essa nova dinâmica em sala de aula, podem não conseguir acompanhar o desenvolvimento da turma e o aprendizado dos estudantes".

Como qualquer metodologia pedagógica, a Aprendizagem Baseada em Problemas também apresenta suas vantagens e desvantagens. Conforme visto no decorrer deste trabalho, o estímulo ao autoaprendizado, a apresentação dos problemas em contextos próximos à realidade e a capacidade de tomar decisões utilizando a interdisciplinaridade de conceitos, são os grandes pontos que corroboram para a utilização do método. Já como desvantagem, a possibilidade de abstração pelo aprendizado e a priorização da prática em detrimento da teoria, foram citadas pelos alunos e docentes do campo pesquisado como sendo os principais empecilhos para a aplicação do método.

Podemos concluir que apesar de estar sendo cada vez mais utilizado e comprovado o seu valor, o PBL não é o "remédio" que irá salvar todos os males que acometem não só o ensino da 
administração, como de qualquer outra área de conhecimento. Ele também não oferece, assim como os modelos tradicionais de ensino, nenhuma segurança de colocação no mercado de trabalho ou uma carreira de sucesso para os alunos que se formam através dela, porém, oferece uma metodologia pedagógica que contribui para formação da autonomia do aluno.

\section{REFERÊNCIAS}

ANDRADE, C. S. O ensino de contabilidade introdutória nas universidades públicas do Brasil. 2002. 55 f. Dissertação (Mestrado em Controladoria e Contabilidade) - Universidade de São Paulo, São Paulo, 2002.

BAZANINI, R.; SANTANA, N.C.; Gestão e conhecimento nas ciências sociais aplicadas: uma experiência didática relacionada ao ensino-aprendizagem da disciplina de Filosofia da Administração. Perspectivas em Gestão \& Conhecimento, João Pessoa, v. 5, n. 1, p. 64-84, jan./jun. 2015.

BERBEL, N. A. N. Metodologia da Problematização: uma alternativa metodológica apropriada ao Ensino Superior. Semina: Londrina, v.16, n. 2, p.9-19, 1995. https://doi.org/10.5433/1679$\underline{0383.1995 v 16 n 3 p 09}$

BOROCHOVICIUS, Eli; TORTELLA, Jussara Cristina Barboza. Aprendizagem Baseada em Problemas: um método de ensino-aprendizagem e suas práticas educativas. Revista Ensaio: Avaliação e Políticas Públicas em Educação, [S.I.], v. 22, n. 83, p. 263-294, abr. 2014.

DIAZ-BORDENAVE, J.; PEREIRA, A. M. Estratégias de ensino-aprendizagem. 28.ed. Petrópolis: Vozes, 2007.

FILHO, E. E; RIBEIRO, L.R.C. Inovando no ensino de administração: uma experiência prática com a Aprendizagem Baseada em Problemas. Encontro de Ensino e Pesquisa em Administração e Contabilidade - EnEPQ, Recife, 2007. p.10.

FREIRE, P. Educação e mudança. Rio de Janeiro: Paz e Terra, 1981.

GUEDES, K. L; ANDRADE, R. O. B; NICOLINI, A. M. Avaliação de estudantes e professores de administração sobre a experiência com a aprendizagem baseada em problemas. Administração: Ensino e Pesquisa. v. 16, n. 1, p. 71-100. 2015. https://doi.org/10.13058/raep.2015.v16n1.201

INSTITUTO NACIONAL DE ESTUDOS E PESQUISAS EDUCACIONAIS. Censo da Educação Superior 2014. Disponível em: <http://portal.inep.gov.br/web/censo-da-educacao-superior>. Acesso em: 28/07/2016.

INSTITUTO ENDEAVOR BRASIL. Pesquisa Empreendedorismo nas Universidades Brasileiras 2014. Disponível em: <http://info.endeavor.org.br/eub2014>. Acesso em 24/07/2015.

MARCONI, M. A.; LAKATOS, E. M. Fundamentos de metodologia científica. 7. ed. São Paulo: Atlas, 2010.

NEVES, A. C. Reflexões sobre o ensino superior de contabilidade e a formação do contador. Revista do Conselho Regional de Contabilidade do Rio Grande do Sul. Porto Alegre, p. 18-29, abr. 2006. 
OlIVEIRA, W. L. A.; ARRUDA, G. H. M.; BITTENCOURT, R. A.. Uso do Método PBL no Ensino de Arquitetura de Computadores. In: INTERNATIONAL CONFERENCE ON ENGINEERING AND COMPUTER EDUCATION, Monguaguá / Santos. Proceedings of the 2007 International Conference on Engineering and Computer Education, 2007.

PÁDUA JÚNIOR, Fábio Pimenta de et al. AVALIAÇÃO DA PERCEPÇÃO DE DISCENTES E DOCENTES SOBRE NOVAS TECNOLOGIAS DE ENSINO EM CURSOS DE GRADUAÇÃO EM ADMINISTRAÇÃO. Administração: Ensino e Pesquisa, [S.I.], v. 15, n. 2, p. 295-321, jun. 2014.

RIBEIRO, L. R. C. Aprendizagem baseada em problemas (PBL) na educação em engenharia. Revista de Ensino de Engenharia, v. 27, n. 2, p. 23-32, 2008.

SOARES, M.A. Aplicação do método de ensino Problem Based Learning (PBL) no curso de Ciências Contábeis: um estudo empírico. 2008. 206 f. Dissertação (Mestrado em Controladoria e Contabilidade) - Faculdade de Economia, Administração e Contabilidade, Universidade de São Paulo, São Paulo.

SOUZA, N. R.; VERDINELLI, M. A. Aprendizagem ativa em Administração: um estudo da Aprendizagem Baseada em Problemas (PBL) na graduação. Revista Pretexto, v. 15, n. NE, p. 29-47, 2014.

ZABALA, A. A prática educativa: como ensinar. Porto Alegre: Artmed, 1998. 